\title{
Variable participation in the defense of communal feeding territories by blue monkeys in the Kakamega Forest, Kenya
}

\author{
Marina Cords ${ }^{1)}$ \\ (Department of Ecology, Evolution and Environmental Biology and New York Consortium \\ in Evolutionary Primatology, Columbia University, $10^{\text {th }}$ floor, Schermerhorn Extension, \\ 1200 Amsterdam Avenue, New York, NY 10027, USA)
}

(Accepted: 17 September 2007)

\begin{abstract}
Summary
While blue monkey groups often defend feeding territories against their neighbours, group members do not participate equally. Data spanning 5 years and 5 wild groups were used to address factors that might explain variable participation, both across age-sex classes and among individual adult females. Adult females participated most, although there was a 9-fold difference between those individuals who participated most and least. Juvenile participation increased with age, but female juveniles participated more than males in each cohort. Male juveniles reduced participation as they approached the age of natal emigration. In general, it seems that adult participation patterns are acquired gradually during ontogeny. Among adult females, those with infants participated less than those without infants, and higher-ranking females participated more than lower-rankers. The presence of matrilineal kin in the group did not generally affect participation by adult females. Age-sex class differences and the effect of infant presence can be explained in terms of relative costs and benefits to participation. The lack of a kinship effect was unexpected. The rank effect was also unanticipated, given that rank does not predict reproductive success in this species. High-ranking females may face lower costs, offer staying incentives to lower-ranked females, or trade services with them.
\end{abstract}

Keywords: feeding territory, territorial defense, intergroup relations.

\footnotetext{
1) Corresponding author's e-mail address: mc51@columbia.edu 


\section{Introduction}

When members of a group collaborate in aggressive defense of a communal feeding territory, there is the potential for a collective action problem. That is, while all members of the group are likely to benefit from the extra food that results from excluding the neighbours, not all are necessarily involved in mounting the territorial defense. In fact free-riding would seem the most rational choice for an individual in such a group-cooperative context, but it would also lead to the dissolution of the collective action, so that no one would benefit (Nunn, 2000).

Nevertheless, collective action persists in animal societies, and it may involve disparate contributions from the various individuals involved. To some extent, disparities are expected if the balance of individual costs and benefits is unequal across potential participants (Nunn, 2000; Wilson et al., 2001; Kitchen et al., 2004). In the case of communal defense of a feeding territory, benefits might vary according to the number of close kin in the group, the effect of an individual's action on the success of the group's defense of its range, and the degree to which participation brings immediate rewards or is traded for other acts of social cooperation. Costs, related generally to the risk of joining potentially violent group-level aggression, may differ across individuals according to their physical condition and life stage. Nunn \& Deaner (2004), for example, studied cooperative territorial defense by female ringtail lemurs. They expected that high-ranking individuals would have more to gain from winning territorial encounters than lower-ranking females, both because higher-rankers could more successfully usurp defended resources and because they might be in better physical condition and, thus, face lower costs while participating. They found that high-rankers did indeed participate more often. Females with infants should bear higher costs of participating than those without infants, and indeed tended to distance themselves from the fray. Other researchers have similarly related inter-individual variation in contributions to range defense, in these cases by males that defended access to mates, to potential cost-benefit variation (Watts \& Mitani, 2001; Kitchen et al., 2004). Watts \& Mitani found that male chimpanzee participation in border patrols was positively associated with direct benefits (namely differential mating success), as well as costs that were apparently low: males who participated frequently seemed to possess skill in handling risks (as evidenced by hunting success). These authors noted that infrequent patrollers might not 
be free-riders, but rather individuals with too little to gain for the costs incurred. There are also cases, however, in which inter-individual variation in participation is minimal (Wilson et al., 2001).

This report characterizes communal territorial defense in an Old World monkey, Cercopithecus mitis stuhlmanni, and focuses particularly on the question of which individuals in the group are most active in defending the group territory. Blue monkeys are often reported as territorial, such that members of one group are aggressive towards those of another group when they meet at range boundaries, and/or home ranges overlap little (Lawes \& Henzi, 1995; Cords, 2002). In high density populations, including the study population in the Kakamega Forest, Kenya, intergroup aggression is the norm: nevertheless, there can be considerable home range overlap between neighbouring groups. The Kakamega monkeys may share up to $50 \%$ of a group's home range, yet long-term study has revealed the consistent mutual antagonism between members of different groups as well as territory boundaries whose positions are remarkably stable over years and even decades. When two groups show peaceful proximity, it is nearly always because each remains on its side of such a boundary, which can be pinpointed to individual trees or general areas on the home range periphery. Incursions into adjacent territories are not infrequent and often seem motivated by attractive food (e.g., a large fruiting tree). When interlopers are detected, they are challenged with vocalizations, and rapid recruitment of the defending group's members leads to their hasty retreat (Cords, 2002). Intergroup hostility seems related to resource defense in a general way. Attractive food sources (like big fruiting trees) on a shared boundary increase the likelihood of aggressive encounters. However, defense of the boundary also seems related to its conventional location. Interlopers are chased even if they are not feeding when discovered, and interlopers always flee when challenged.

Intergroup encounters in the study population never involve all group members. Longer-lasting encounters, which are usually more escalated, generally include more participants. The behaviour of those individuals that are involved also varies. Some are on the frontline, facing off, chasing or grappling with opponents. Some vocalize from a safer distance. Others watch, but do not contribute to threatening behaviour except, perhaps, by being there. The goal of this study was to quantify variable participation in aggressive intergroup encounters, and to explore some of the factors that may account for 
it. The focus is on adult females and juveniles only, for, while adult males often punctuate intergroup encounters with vocalizations, and sometimes join in threatening members of an opposing group, they are generally far less active, and less likely to engage in chases and contact aggression, than adult females (Cords, 2002; Payne et al., 2003a).

\section{Methods}

The study population inhabits the Kakamega Forest, western Kenya $\left(0^{\circ} 19^{\prime} \mathrm{N}\right.$, $34^{\circ} 52^{\prime} \mathrm{E}$, elevation approx. $1650 \mathrm{~m}$ ), a wet tropical forest receiving about $2 \mathrm{~m}$ of rain per year. The forest supports a high density of blue monkeys (approx. 170-220 individuals $/ \mathrm{km}^{2}$, Fashing \& Cords, 2000), as well as other primate species. Data come from five social groups, each monitored for a $2-5$ years period between 2002 and 2006 inclusive. One trio of groups consisted of a parent group (Tw) that fissioned (into Tws, Twn) in April 2005. The other two groups (Gn, Gs) were the results of an earlier (1999) fission. Groups ranged in size from 19 to 59. As is typical of blue monkeys, most groups had a single resident adult male and multiple adult females; however, one group (Tws) contained three or more males for a period of 1.5 years. All individuals in all groups were individually identified based on natural features. Each group had 1-3 of the other study groups as neighbours.

During the study period, observers followed each group nearly every day to monitor various aspects of social behaviour. Whenever observers detected members of their focal group responding behaviourally to neighbouring groups in any way (including alarm chirps, aggressive growls, bodily threats and flight), they noted the identity of interacting groups, timing of the encounter, which individuals participated (and how), and the encounter outcome. Only some of the participating individuals could be individually recognized in each encounter because encounters often occurred high in the canopy and involved rapid movement. There is no reason, however, to think that missing records would be non-randomly distributed among group members. Because other kinds of data collection were occurring during daily group follows, there was variation across groups and years in terms of the effort devoted to documenting participation in intergroup encounters. This led to differences in the total number of encounters recorded (172-254 per calendar year, 89-195 during the part-year periods in 2005 for Tw, Tws and 
Twn groups, see below), as well as the density of records of individuals participation (minima always 0 per group year, maxima ranging from 11 to 50). In comparisons across group-years, results are, therefore, generally presented in a relative way.

We counted an animal as participating in an intergroup encounter if it vocalized aggressively (pyows and booms by adult males, growls and chirps by others), threatened members of the opposing group non-vocally (including stare-threats, open-mouth threats, lunge-threats, head-bobs and supplants), chased, or had physical contact with members of opposing groups. Individuals who were merely present, or who only received aggression from other groups without also participating in one of the above ways, were not included as participants. Most participating individuals showed multiple types of behaviour in a given encounter: in the analyses, I represented the individual's behaviour as the most intense level of participation observed, where intensity increased from vocalization to physical threat to chasing and to physical contact.

For analysis, I summarized data across all encounters for a given group for each calendar year. For the Tw, Tws and Twn groups, data from 2005 were examined in periods of less than 12 months, because of the group fission that occurred in April. Raw participation scores were corrected for an individual's time in the group (a few animals died, some older juvenile males emigrated). Analyses by group-year made it possible to relate participation to age-sex class and dominance rank, both of which changed across years. Also, analysis by group-year allowed some control for the different visibility of study groups and for variation in observer effort to collect data on intergroup encounters. For the same reasons, comparisons or summaries of participation scores across years are standardized relative to adult females. Most statistical tests were carried out on data from each group-year (in the case of Tw, Tws and Twn, 2005 was a partial year). Immature individuals often appeared in different age classes in their groups from year to year, and individual adult females often appeared repeatedly in that age-sex class in multiple years. When the tests on individual group-years suggested a common trend, I used Fisher's method for combining $p$-values (Sokal \& Rohlf, 1981, p. 779) to evaluate the overall results.

Blue monkeys at Kakamega reproduce seasonally, with births clustered in January-March (Chowdhury \& Cords, data not shown). Adult females were counted as having an infant in a given year if they had an offspring under the 
age of one year for at least 6 months. Females with infants that died young were, thus, excluded from this class. Matrilineal kinship was known from pedigree records going back to 1978 in Tw, Tws and Twn, and to 1992 in Gs and $\mathrm{Gn}$. Because infants could not always be recognized through to adulthood before about 1997, I used data from 2005 and 2006 only to evaluate the effect of family size on participation in intergroup encounters. I considered all matrilineal relatives as well as only close kin, which included mothers, offspring and siblings. Paternity was not known, so kinship was assessed only via matrilineal lines. The dominance rank of adult females was assessed using the program Matman (Noldus Information Technology, Wageningen, The Netherlands; de Vries, 1998), with input data consisting of all dyadic agonistic interactions, in which only one partner exhibited submissive behaviour, among adult females for a given year (or shorter period for Tw, Tws and Twn in 2005).

\section{Results}

Age-sex class differences in participation

Adult males did not participate at all in most $(69 \%, N=2932$ group-specific records) intergroup encounters. If we exclude from consideration male participation that was merely vocal (booms and pyows), $87 \%$ of encounters did not include male participation. Males were never aggressive to neighbouring groups on their own and never initiated aggressive intergroup encounters. When they did participate, it always seemed that adult males were backing up their own females, and their interactions with members of other groups were typically brief when they occurred. Thus, as others have previously reported, territorial defense is carried out mainly by other group members, and further analysis focused on them.

Nearly all adult females were observed to participate in intergroup encounters in each year, while the proportion of individuals participating among juvenile age classes was consistently smaller, although it generally increased with age (Figure 1). A larger fraction of adult females participated intensely (chases and physical contact) relative to all other age classes. Intense participation was virtually absent among young juveniles. Only one infant was observed to participate in an encounter one time. 


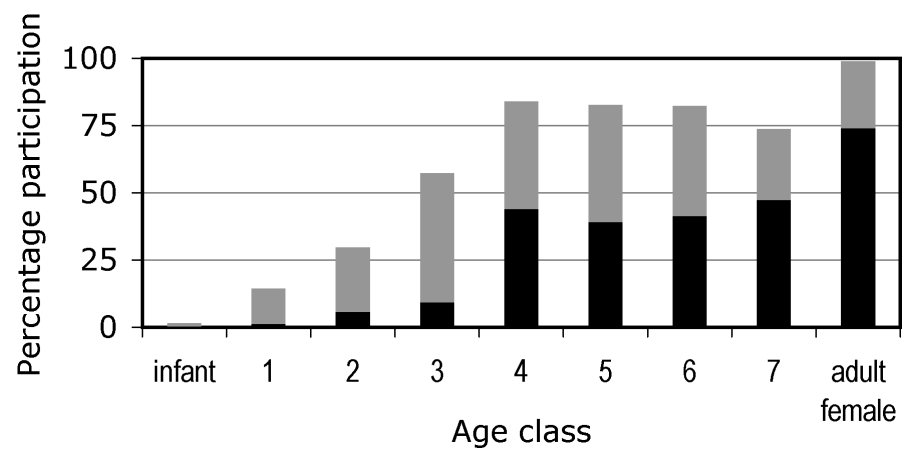

Figure 1. Percentage of individuals in each age class, from infants to adult females, that participated (in a given year) in intergroup encounters. The proportion was calculated across 16 group years by dividing the total number of individuals who participated by the total number of individuals in each age class (represented by annual cohorts). Black areas show intense participation (chasing and physical contact), grey bars show milder forms of participation (threats and vocalizations).

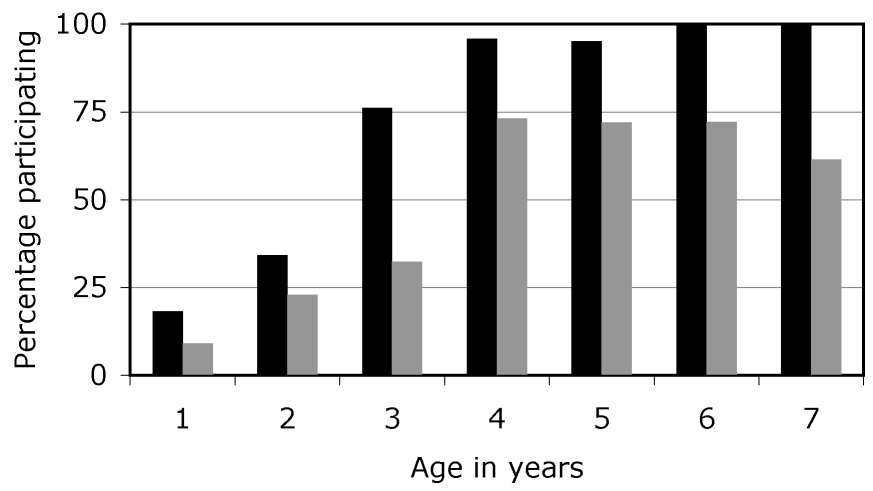

Figure 2. Percentage of female (black) and male (grey) juveniles from age 1 to age 7 years that participated in intergroup encounters across 16 group-years. Both milder and intense forms of participation are included.

In every juvenile age class, the proportion of females that participated exceeded the proportion of participating male peers (Figure 2), and this was true whether all participation or only intense participation was considered. For juvenile females, the proportion of individuals that participated in intergroup encounters increased with age. For male juveniles, the highest proportion of participation peaked for 4-6 years olds, but dropped for 7-year-old individuals. Blue monkey males disperse from their natal groups at the mean age of 7.3 years (Ekernas \& Cords, in press). 
Not surprisingly, the amount of participation also differed among age-sex classes in every group year (ANOVA, 5.431 $<F<24.52, p \leqslant 0.0059$, tests for 15 group-years). Fisher PLSD tests (experimentwise error $<0.05$ ) consistently identified adult females as differing from juveniles in each group year, although differences with older juveniles were often not significant: females differed from 5 years olds in only 3 of 9 group-years when they were present, from 6 years olds in 3 of 7 group-years, and from 7 years olds in 2 of 6 group-years. In some cases, older juveniles also differed from younger juveniles, whose participation scores were consistently low. Even if we exclude juveniles that did not participate at all, there were marked differences between the participation levels of the remaining juveniles and adult females (Figure 3). These differences increased consistently as juvenile age decreased.

Although adult females participated the most, variation among individual adult females was often substantial. In three group-years, there was one female per group that was never observed to participate (a different individual in each case), while the maximum score was 50. Averaged across the 13

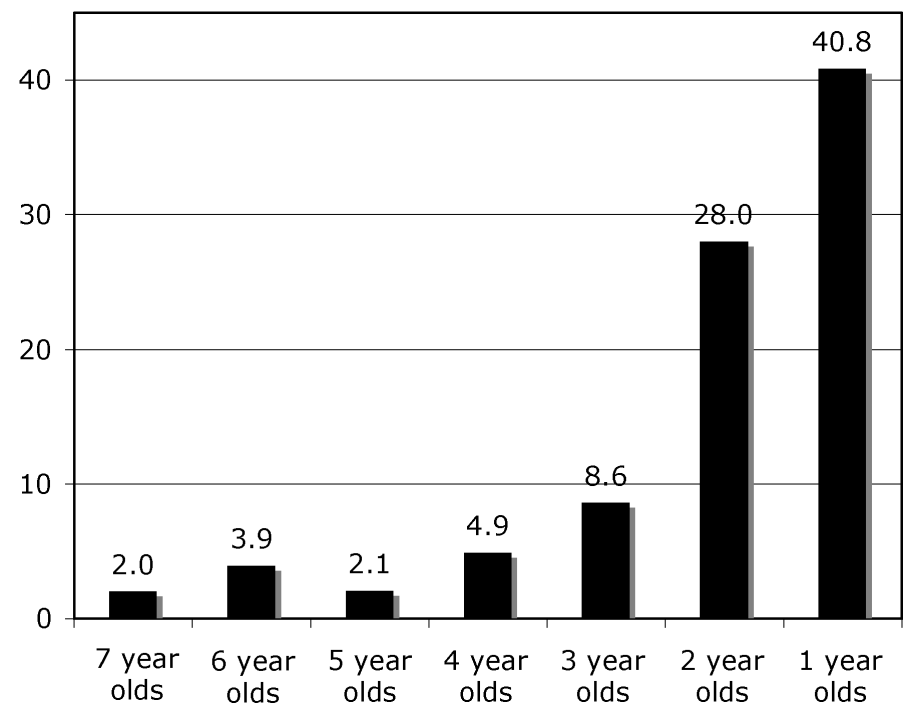

Figure 3. Participation of juveniles aged 1-7 years in comparison to adult females. Each bar shows the amount by which participation of adult females exceeds that of juveniles in each age class, averaged across the group years in which such juveniles were both present and participating ( $N=5$ for 7 -year-olds, 8 for 6 -year-olds, 9 for 5 -year-olds, 10 for 4 -year-olds

11 for 3 -year-olds, 10 for 2-year-olds and 5 for 1 -year-olds). 
group-years in which the minimum participation score exceeded zero, the female who participated most exceeded the female who participated least by a factor of 9 (range 3.5-17.9). Intense participation was less variable, perhaps because it was less frequent and sample sizes were smaller. In 14 of 16 group-years, the minimum score for intense participation was zero, while the maximum, across all group-years, was 11 .

\section{Presence of an infant}

Females with infants participated less often than other adult females. This pattern was significant for 6 of the 13 group-years in which there were at least 2 females with infants in a group ( $t$-tests, $0.0026<p<0.0374)$, and mean participation rates were higher for females without infants in 6 of the 7 remaining group-years. Combining tests across all 13 group-years, this pattern was strong $\left(\chi^{2}=78.43,26 \mathrm{df}, p<0.001\right)$. These results were essentially identical if only intense participation was considered; 4 of 13 groups showed a significant difference, 7 of the remaining 9 tended in the same direction, and the combined test showed a strong effect $\left(\chi^{2}=66.90\right.$, $26 \mathrm{df}, p<0.001)$.

\section{Matrilineal family size}

The frequency with which adult females participated in intergroup encounters was neither universally correlated with the total number of matrilineal kin in the group, nor with the number of close kin (siblings, offspring, mother). For two of the eight group years, females with a larger number of kin participated more often $(r=0.741, N=8$, one-tailed $p<0.025$, Twn 2006, and $r=0.586, N=12$, one-tailed $p<0.01$, Gn 2006), but six other group-years showed no significant correlation, and in three of these cases, the correlation coefficient was negative. When analysis was limited to close kin, there were again two of eight group years in which females with more kin participated more often $(r=0.735, N=8$, one-tailed $p<0.25$, Twn 2005, and $r=703, N=8$, one-tailed $p<0.05$, Twn 2006), but the remaining cases showed no significant relationship. If analyses were limited to intense participation, the effect of family size was even weaker.

\section{Dominance rank}

Female ranks were significantly linear in 15 of 16 group-years. In three of these 15 group years, high-ranking females participated in intergroup encounters significantly more often than low-ranking females $\left(r_{\mathrm{s}}=0.491\right.$, 
two-tailed $p=0.0374$ for $\mathrm{Gs}$ in 2003; $r_{\mathrm{s}}=0.39, N=25, p=0.055$ for Tw in 2004; $r_{\mathrm{s}}=0.78, N=8, p=0.037$ for Twn in 2006). Correlation coefficients, while not statistically significant, were similarly positive in eight of the remaining 12 group years. Thus, across all group years, there was a significant effect of dominance rank on participation $\left(\chi^{2}=52.60,30\right.$ df, $p<0.01)$. Results were very similar if only intense participation was included in the analysis, with 3 significant correlations, and 11 of 13 other group years having positive correlations; the combined result was even stronger $\left(\chi^{2}=65.94,30 \mathrm{df}, p<0.001\right)$.

\section{Discussion}

Blue monkeys exemplify a group-territorial species, whose defended area has recognizable spatially-explicit boundaries. Adult females are the primary defenders of the communal territory, but results presented here show that individuals grow into this role. Juveniles generally increase their participation with age, and sex differences emerge during the juvenile period that match the sex difference of adults. In particular, female juveniles were consistently more likely to participate than their male peers, and juvenile males that are about to emigrate from their natal groups invest relatively little in defense of their group's feeding grounds.

It is probable that these ontogenetic changes and sex differences relate to the relative costs and benefits of territorial defense. Given that these are feeding territories, and given that relative reproductive success of females, as opposed to males, depends most closely on access to adequate nutrition, it makes sense that females would consistently participate at higher rates than males do. The oldest juvenile males have particularly little to gain, as they will soon emigrate from their natal groups. One might ask why juvenile males participate at all in intergroup encounters if their stay in the group is only temporary. It is possible that the immediate direct benefits of ensuring access to feeding sites are worth the costs, that participation brings other benefits not measured in this study (such as social tolerance or receipt of grooming), or that benefits to female relatives, who maintain the same territorial boundaries over lifetimes, ultimately pay off the effort and risk involved.

Although virtually all adult females participate in intergroup encounters, there was nearly an order of magnitude difference in the degree of participation between the most and least involved. The presence of a young infant seems to be one factor relevant to explaining this variation. Females 
with infants may face higher risks in participating, both because they are physically encumbered when carrying an infant, and because a small infant is particularly vulnerable to aggression. Aggression in the intergroup context, especially in the more escalated encounters, is generally wilder than in the within-group context: there is often considerable rapid leaping between and within trees, as phalanxes of individuals from one group supplant and flee from the neighbours. The presence of multiple individuals in the same branches limits freedom of movement that can be important in escapes. The two most severe wounds ever witnessed on an adult female in this population were the results of between-group aggression (Cords, 2002; pers. obs.), and fatal attacks on extra-group females in other guenons have been reported (McGraw et al., 2002; Payne et al., 2003b), though neither was associated with an intergroup encounter. Another cost that may inhibit mothers from participating is energetic: energetic demand results both from the often vigorous activity involved in defensive action, and from missed feeding time.

The size of the matrilineal family did not seem to affect the likelihood of participation among adult female blue monkeys. In the few cases when there was a significant effect, it was positive, but in most cases, there was no discernable effect. In other primates, kinship has been implicated as a factor explaining variable participation in communal range defense. Kitchen et al. (2004), studying male black howler monkeys, found that subordinate males with long-term relationships to dominant adults were more likely to participate in intergroup encounters: the authors suggested that animals with long-term relationships might well be related. Nunn \& Deaner (2004) studied female ringtail lemurs, and found higher rates of aggression in intergroup encounters in females with more daughters in the group. They also found less variance in participation in one of two groups with the higher average degree of relatedness. Further study will be needed to rule out kinship as a relevant variable in the Kakamega blue monkeys. Kinship could affect more than overall participation levels: for example, kin might be more likely to join one another in any given fight. In addition, the inclusion of paternal kinship as a factor predicting differential participation may prove important (Silk, 2006).

Females with high dominance rank generally participated more than those with lower ranks. Others have reported similar rank effects in species whose females defend territorial boundaries (Payne et al., 2003a for female samangos, although removal of two females with anomalous values was required to detect the effect; Nunn \& Deaner, 2004, female ringtail lemurs). Nunn \& 
Deaner interpreted this pattern as resulting from the greater benefit that socially dominant individuals have in terms of access to food. In blue monkeys, however, effects of rank on feeding and birth rate appear negligible (Cords, 2002; Pazol \& Cords, 2005), leaving open the question why higher-ranking females participate more often. At least three possible answers may exist. First, while all group members presumably benefit from securing access to their food supply, costs of participation in intergroup aggression could be lower for higher-ranking females, especially if their social rank reflects success in aggressive interactions generally. At present, the factors influencing dominance rank in adult female blue monkeys are not fully understood (Cords, 2002), but it is true by definition that higher-ranking females are accustomed to prevailing in aggressive interactions with a wider variety of partners (Cords, 2000).

A second possibility is that increased participation by high-ranking females is a 'staying incentive' offered to lower-ranked females (Keller \& Reeve, 1994). Group fissions do occur in blue monkeys, resulting in sister groups of unequal size that appear to be organized along matrilineal lines (Cords \& Rowell, 1986; Cords, unpubl.). In the one (2005) fission that occurred when we had good knowledge of rank and matrilineal relations, several low-ranking matrilines split from a high-ranking matriline that ended up in a much smaller group. The small group consistently lost the initial territorial encounters against the larger sister group following their fission and was, therefore, ultimately forced to a marginal area of the original group's range. This area appeared less desirable, in that it had been used relatively infrequently before the fission occurred. Division of the range was similarly determined by the relative size of the new sister groups in two earlier fissions. Thus, while group fission presumably occurs because most individuals are disadvantaged in a very large group relative to living in smaller groups, it seems that consequences for sister groups of unequal size can be quite different. Furthermore, lower-ranking females may be able to influence how a group splits and, thus, affect not only their own position in the new groups but also that of high-ranking females. Lower-ranking females can either opt not to join the high-rankers, or may actively and collectively exclude them. In the 2005 fission, for example, we observed lower-ranking members from the larger group harassing a relatively high ranking matriarch: they successfully kept her out of their group, even though she seemed highly motivated to join it as it included all of her progeny. These observations suggest that 
it is in the best interest of high-ranking females to remain in the top ranks of a larger sister group rather than risk being abandoned in a small group by low-rankers looking for advantages elsewhere. Staying incentives could perpetuate such an arrangement.

Finally, it remains possible that high-ranking females trade their services in communal territorial defense for other services offered to them by lowerranking females. Because coalition formation is extremely rare in this species (Cords, 2000), and because high-rankers already have an advantage in terms of tolerance in feeding trees, grooming seems the most likely candidate service. Cords (2000) and Pazol \& Cords (2005) did not find any rank effect on grooming among adult females, but further examination of this possibility may be merited, and remains part of our current research agenda.

In conclusion, certain aspects of variable participation in intergroup aggression in blue monkeys, such as differences among age-sex classes and lower participation by females with infants, seem explicable in terms of relative costs and benefits to the participants. A lack of maternal kinship effects was not expected, and the presence of rank effects was also unanticipated in a species where rank affords no apparent reproductive advantage. Collectively, these results, as well as the variation that occurred among group-years, suggest that there must be additional sources of variation that have not yet been measured.

\section{Acknowledgements}

I am grateful to the Ministry of Science, Education and Technology, Government of Kenya, for permission to work in the Kakamega Forest, to the University of Nairobi, Institute of Primate Research and Moi University for local sponsorship, and to the staff at the Kakamega Forest Station for their cooperation. Long-term funding for this work has been provided by Columbia University, the L.S.B. Leakey Foundation, the Wenner Gren Foundation, AAAS, and the National Science Foundation (BCS 9808273, BCS 0554747). I thank many Kenyan and American field assistants for their contributions, especially P. Akelo, M. Atamba, S. Brace, N. Cohen, S. Maisonneuve, C. Makalasia, K. McLean, N. Mitchell, B. Pav, A. Piel, M. Sheehan, E. Shikanga, B. Shimenga and E. Widava. K. King and K. Laumann helped with data organization. I am grateful to Mike Wilson for inviting me to participate in this special issue, and to Peter Henzi and an anonymous reviewer for comments on the manuscript.

\section{References}

Cords, M. (2000). Agonistic and affiliative relationships in a blue monkey group. - In: Old world monkeys (Whitehead, P.F. \& Jolly, C.J., eds). Cambridge University Press, Cambridge, p. 453-479. 
Cords, M. (2002). Friendship among adult female blue monkeys (Cercopithecus mitis). Behaviour 139: 291-314.

Cords, M. \& Rowell, T.E. (1986). Group fission in blue monkeys of the Kakamega Forest, Kenya. - Folia Primatol. 46: 70-82.

De Vries, H. (1998). Finding a dominance order most consistent with linear hierarchy: a new procedure and review. - Anim. Behav. 55: 827-843.

Ekernas, L.S. \& Cords, M. (in press). Social and environmental factors influencing natal dispersal in blue monkeys, Cercopithecus mitis stuhlmanni. - Anim. Behav.

Fashing, P.J. \& Cords, M. (2000). Diurnal primate densities and biomass in the Kakamega Forest: an evaluation of census methods and a comparison with other forests. - Am. J. Primatol. 50: 139-152.

Keller, L. \& Reeve, H.K. (1994). Partitioning of reproduction in animal societies. - TREE 9: $98-102$

Kitchen, D.M., Horwich, R.H. \& James, R.A. (2004). Subordinate male black howler monkey (Alouatta pigra) responses to loud calls: experimental evidence for the effects of intragroup male relationships and age. - Behaviour 141: 703-723.

Lawes, M.J. \& Henzi, S.P. (1995). Inter-group encounters in blue monkeys: how territorial must a territorial species be? - Anim. Behav. 49: 240-243.

McGraw, W.S., Plavcan, J.M. \& Adachi-Kanazawa, K. (2002). Adult female Cercopithecus diana employ canine teeth to kill another adult female $C$. diana. - Int. J. Primatol. 23: 1301-1308.

Nunn, C.L. (2000). Collective benefits, free riders, and male extra-group effort. — In: Primate males: causes and consequences of variation in group composition (Kappeler, P.M., ed.). Cambridge University Press, Cambridge, p. 192-204.

Nunn, C.L. \& Deaner, R.O. (2004). Patterns of participation and free riding in territorial conflicts among ring-tailed lemurs (Lemur catta). — Behav. Ecol. Sociobiol. 57: 50-61.

Payne, H.F.P., Lawes, M.J. \& Henzi, S.P. (2003a). Competition and the exchange of grooming among female samango monkeys (Cercopithecus mitis erythrarchus). - Behaviour 140: 453-471.

Payne, H.F.P., Lawes, M.J. \& Henzi, S.P. (2003b). Fatal attack on an adult female Cercopithecus mitis erythrarchus: implications for female dispersal in female-bonded societies. Int. J. Primatol. 24: 1245-1250.

Pazol, K. \& Cords, M. (2005). Seasonal variation in feeding behaviour, competition and female social relationships in a forest dwelling guenon, the blue monkey (Cercopithecus mitis stuhlmanni), in the Kakamega Forest, Kenya. — Behav. Ecol. Sociobiol. 58: 566577.

Silk, J.B. (2006). Practicing Hamilton's rule: kin selection in primate groups. — In: Cooperation in primates and humans (Kappeler, P.M. \& van Schaik, C.P., eds). Springer, Berlin, p. $25-46$.

Sokal, R.R. \& Rohlf, F.J. (1981). Biometry. - W.H. Freeman, San Francisco, CA.

Watts, D.P. \& Mitani, J.C. (2001). Boundary patrols and intergroup encounters in wild chimpanzees. - Behaviour 138: 299-327.

Wilson, M.L., Hauser, M.D. \& Wrangham, R.W. (2001). Does participation in intergroup conflict depend on numerical assessment, range location or rank for wild chimpanzees? — Anim. Behav. 61: 1203-1216. 